\title{
RESULTS OF SURGICAL TREATMENT FOR PULMONARY ATRESIA
}

\author{
BY \\ MAURICE CAMPBELL \\ From the Cardiac Department, Guy's Hospital, and the Institute of Cardiology \\ Received December 3, 1959
}

Most cases of pulmonary atresia have the general anatomical features of Fallot's tetralogy with atresia at or near the pulmonary valve instead of stenosis, but in one quarter of the necropsy cases the ventricular septum is intact instead of having a defect $(24 \%$, Peacock, 1866 , and Abbott, 1936). The general features, based on six cases with necropsy, have been discussed by Allanby et al. (1950): five of these were of the common type and one of the less common type. Subsequent experience has made us think that the latter is even less common than this, since it was found in only one of our fourteen necropsies, perhaps because our experience is with older children.

The clinical features are like those of Fallot's tetralogy. East and Barnard (1938) thought that the diagnosis should be made more often on clinical grounds, and Taussig (1947) emphasized the loud single (aortic) sound well-heard in the pulmonary area and the absence of a systolic murmur. The circulation to the lungs must come from the aorta through a persistent ductus or enlarged bronchial arteries, more often the latter. In about half the cases there is a continuous murmur from some of these vessels, but in the other half no such murmur is heard, perhaps because the circulation to the lungs is maintained by a large number of smaller arteries.

The shadows in the lungs from the numerous bronchial arteries, seen both with ordinary radiology and even more clearly with angiocardiography, are the other main diagnostic feature: they have been described by Campbell and Gardner (1950). The absence of the hilar comma that represents a properly filled pulmonary artery (Fig. 1 and 2), often replaced by some unusual artery (Fig. 3), and the deep, rounded pulmonary bay, often with unusually sharp definition, indicate an anomalous pulmonary blood supply. Dense vascular shadows, high in the mediastinum, sometimes best seen below the aortic arch in the left anterior oblique position with angiocardiography, and nodular hilar structures with unusual branching in the lung fields are good evidence of hypertrophied bronchial arteries.

The commoner form of pulmonary atresia has been considered as a variety of Fallot's tetralogy. In a follow-up of patients after subclavian-pulmonary anastomosis (Campbell and Deuchar, 1953) we included 20 such cases: the high mortality and relatively poor results made us doubtful about the advisability, of operation, but a few results were so good that it can not be discarded. Taussig and Bauerfeld (1953) and White et al. (1956) also found the results less good than those for Fallot's tetralogy.

The special problems involved in the surgical treatment of pulmonary atresia-the small thinwalled pulmonary artery that is often unsuitable for an anastomosis, and the importance of not dividing too many of the small collateral vessels that carry the main blood supply to the lungsmade us think that pulmonary atresia should be recognized as a separate entity and should not be included with Fallot's tetralogy (Allanby et al., 1950). In a more recent follow-up of the results of operation for Fallot's tetralogy (Campbell, 1958), we excluded them, so are considering them here.

\section{RESULTS OF OPERATION}

Of our patients with pulmonary atresia, 27 have had an operation, 20 of these in the years 1948-51. In five this was no more than a thoracotomy for the pulmonary arteries proved unsuitable 


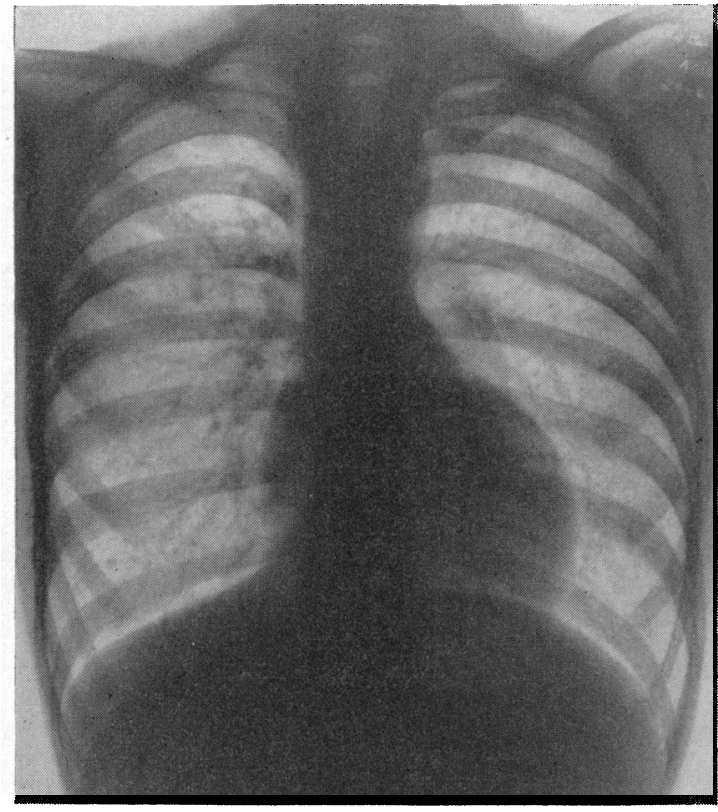

FIG. 1-Teleradiogram of a boy with pulmonary atresia and a bronchial artery blood supply to the lungs. The nodular shadow seen in the left hilum is characteristic of a dilatation of the pulmonary artery where no blood supply is received from the pulmonary trunk but a bronchial artery is anastomosing with the pulmonary artery. A small pulmonary artery and some collateral arteries are seen in the right lung. Case 0833.

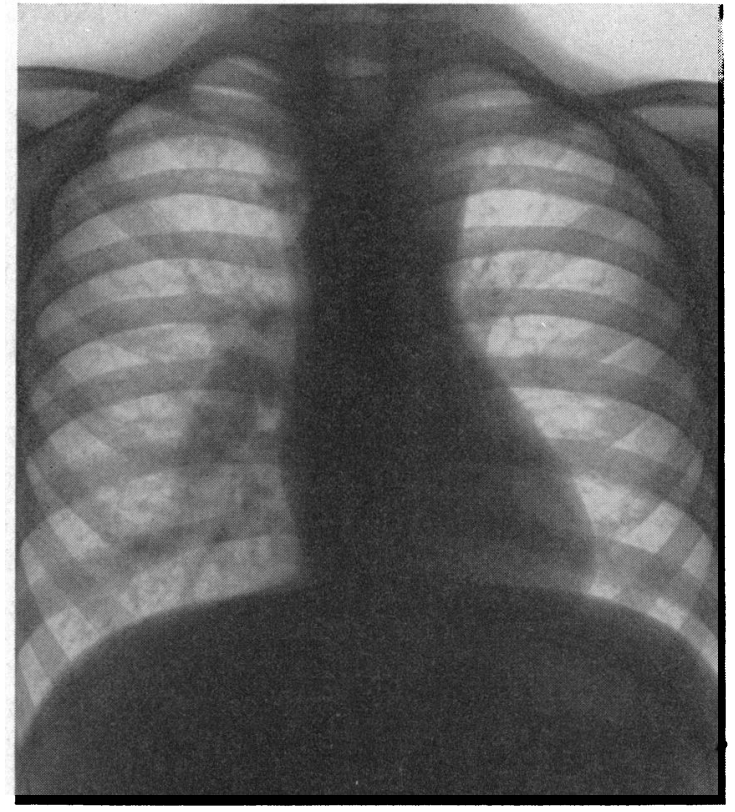

FIG. 2.-Teleradiogram from a girl thought to have pulmonary atresia and a right pulmonary artery supplied through a persistent ductus or other collateral artery. Both lungs, especially the left, are oligæmic, but after a left-sided subclavianpulmonary anastomosis, the left pulmonary artery, which can hardly be seen, became as prominent as that on the right. There is a right-sided aortic arch and probably bilateral superior venæ cavæ. Eleven years after operation, she is still able to lead a normal life. Case 0096.

for any anastomosis, and in four the anastomosis had to be end-to-end instead of end-to-side for the same reason. We have nothing to say about direct operation, for as a rule the atretic portion is of some length and would need major reconstructive surgery, which may become possible with open heart surgery. In very rare cases, the outflow tract is relatively normal and the atresia is of the valve alone and would be easy to improve at operation; but we have seen this condition only once at the valve at a necropsy and once at the infundibulum when it was recognized on angiocardiography (see later).

Operative Mortality. This is extremely high $(37 \%)$ as 10 of the 27 patients died. The percentage may be too high as all patients with pulmonary atresia who died must have been included, but some who did well may have been unrecognized and included as Fallot's tetralogy. Since this was written, Dr. Deuchar has given me a good example.

A boy, aged 5 (in 1948), was thought to have Fallot's tetralogy and had a subclavian-pulmonary anastomosis: an artery entering the pulmonary artery was seen and was thought to be a persistent ductus but was more likely a large bronchial artery. He was greatly improved and maintained this for eight years. He then began losing ground and was unable to earn a living. He was re-investigated ten years after the first operation and was found to have a localized pulmonary atresia, so a further operation was advised. There was a diaphragmatic atresia in the infundibulum. This was opened but no attempt was made to close the ventricular septal defect, and he was unable to stand the greatly increased blood flow to the lungs and died later that day. 


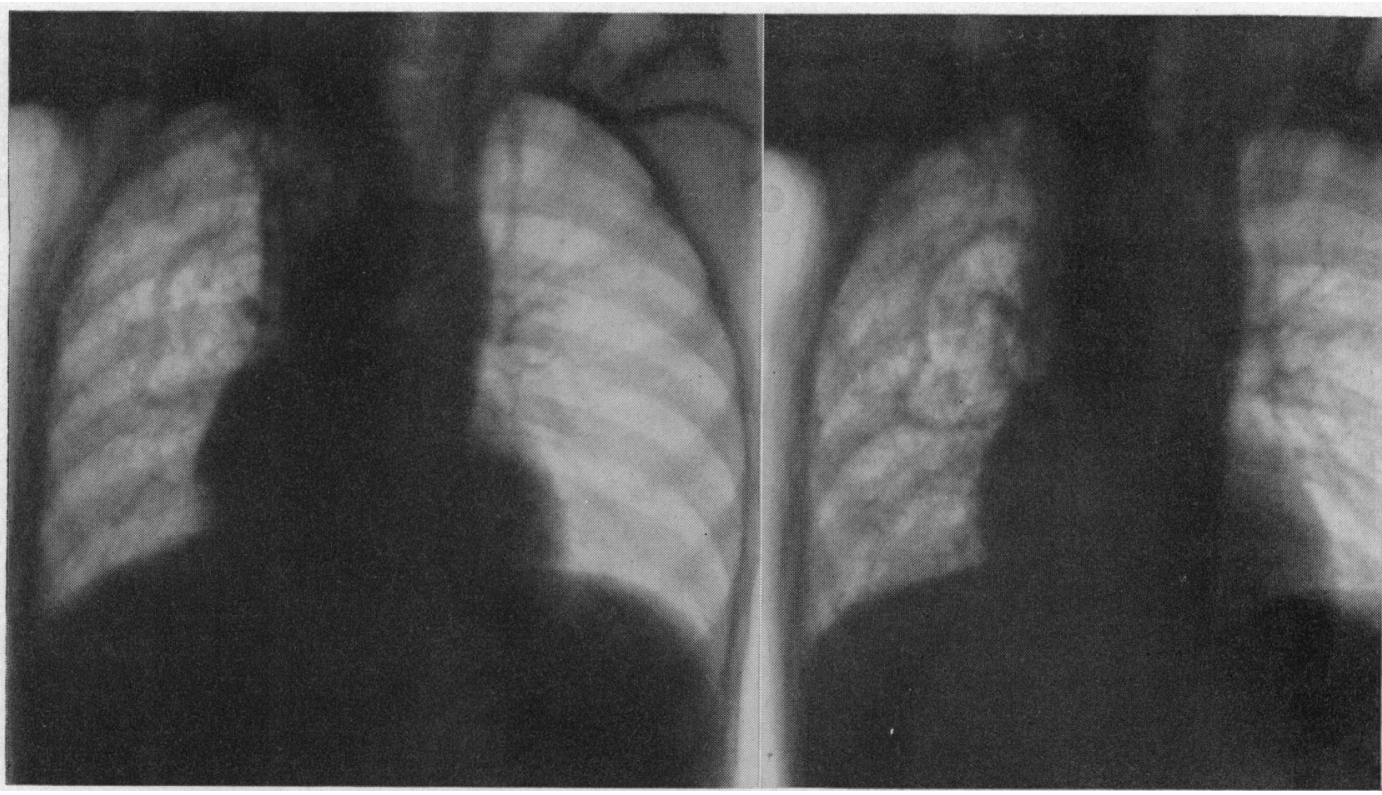

Fig. 3.-Angiocardiograms of a girl with pulmonary atresia and unusual collateral arteries. (A) At 4 seconds, showing most of the heart and the large aorta well-filled with diodone. There is little filling of the lung fields except for the unusual collateral arteries. (B) At 5 seconds, the right lung is now much better filled. There is less change in the left though there is now a doubtful shadow of a small left pulmonary artery, which was in fact found at operation. Case 0027.

This great contrast with Fallot's tetralogy in the operative mortality is, we think, because some of the many hypertrophied arteries carrying blood to the lungs are inevitably lost by division at operation, and the increased blood supply from the new anastomosis is not large enough to balance this and at the same time to improve the patient enough to carry him through the difficulties of the post-operative period.

Patients who Died. In addition to the ten who died soon after operation, one died four years later and a second six years later. Of these 12 patients, 5 had continuous murmurs and 7 had not. Of the first five, one had a closed ventricular septum and a pulmonary blood supply through a large left-sided patent ductus (Case 1, Allanby et al., 1950). The other four were of the commoner type with a ventricular septal defect. The second had situs inversus and the blood supply to the lungs through a right-sided patent ductus. The third had a left-sided patent ductus, cor biloculare, and isolated lævocardia (Campbell et al., 1952). The fourth had a blood supply to the lungs through bronchial arteries and an anomalous artery from the aortic sinus (Case 6, Allanby et al., 1950). The fifth died six years after his operation from an infected pneumo-hydro-thorax. There was no pulmonary trunk and the aorta divided into two, each division giving off a large artery (? bronchial, ? ? pulmonary) to the lung of that side: the two divisions finally joined to form a normal descending aorta: it is still difficult to be sure if this was a case of pulmonary atresia or of persistent truncus arteriosus (0087).

The blood supply to the lungs was through bronchial arteries in 6 of the 7 where no continuous murmur had been heard. This absence was surprising in some of these cases, as one or two of the bronchial arteries were quite large. One patient had a narrow and tortuous but patent ductus as well as two larger bronchial arteries (A 3812). Full notes of the seventh who obtained a very good result but died after four years, are given later (see p. 531).

Patients who Did Not Benefit. There were another $7(26 \%)$ who did not obtain any benefit, generally because it was found at thoracotomy that nothing could be done. Of the two who could 
have an anastomosis but obtained little or no benefit, one had it between the subclavian and pulmonary arteries (0085); and the other, a girl aged 5 with a continuous murmur, had a Pott's operation (0683). In one of the other three with a continuous murmur (0121) there were too many collateral vessels to dissect out the pulmonary artery: in the other two (0222 and 0087) no pulmonary artery (or patent ductus) could be found, and in the second of these, the patient who died six years later,(see above) a large artery that appeared to come from a right-sided aortic arch descended rather vertically to the right lung. In the sixth (0149) there was a large aorta on the left curving over to descend on the right, and where the left pulmonary artery should have been a leash of small collateral vessels and two larger bronchial arteries. The seventh (0272) was somewhat similar. The exact diagnosis is still unproved but five at least seemed to be ordinary cases of pulmonary atresia, though in the last two it is more difficult to exclude truncus arteriosus.

Good Results. Ten patients $(37 \%)$ were able to do much more after the operation, and generally the improvement has been maintained for from 6 to 11 years. In 6, a continuous murmur had been heard but in the other 4 it had not. In general, those with and those without continuous murmurs behaved in much the same way and had an equal share of the good and bad results.

(a) Patients with a Continuous Murmur. In these 6, the results were very good in the first two, good in the third and fourth, and great improvement in the last two. All were thought to have pulmonary atresia and generally this was confirmed at operation: in the first and third the blood supply to the lungs was through a persistent ductus and in the other four it was thought to be through hypertrophied bronchial arteries (Fig. 1). The anastomosis had to be an end-to-end one in three patients, but all of them proved satisfactory.

The first, a girl aged 8, who was thought to have pulmonary atresia with a persistent ductus on the right (Fig. 2), obtained an excellent result. Instead of being an invalid who could walk 200 yards, she could soon lead a normal life, later working in a shop, and could walk four miles, including many of the Devonshire hills. Her colour was greatly improved and the hæmoglobin percentage fell from 126 and remained between 104 and 110 per cent. Her heart, which had been small, increased soon after operation (c.t.r. 48 to 53) and then remained at this size. Her condition is still excellent after eleven years (0096).

The second, a boy aged 5, had a subclavian anastomosis to a thin-walled pulmonary trunk and obtained an equally good result. He can walk two miles and even run a short distance, with a colour that is nearly normal, although he had been able to walk no more than 200 yards and often had retrosternal pain. His hæmoglobin had fallen from 146 to 110 per cent and his heart became rather larger (c.t.r. $48 \%$ before and $54 \%$ eight years later). He has maintained his improvement for eight years, though his kyphoscoliosis

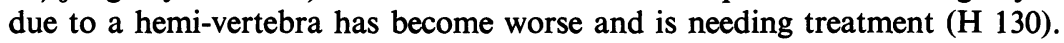

The third, a girl aged 11, was thought to have pulmonary atresia with a patent ductus. After an end-toend left subclavian-pulmonary anastomosis, leaving the right pulmonary artery supplied through the ductus, she could walk two miles on a warm day instead of 50 yards: the heart size had not increased (c.t.r. $53 \%$ ) and her hæmoglobin was 124 instead of 141 per cent. After nine years she is much the same, able to lead a comfortable quiet life, but unable to earn her living or to do much in the winter (0525).

The fourth, a girl aged 5, was greatly improved after an end-to-end subclavian-pulmonary anastomosis. Six years later, she could still walk a mile instead of a hundred yards: her hæmoglobin had fallen from 148 to 114 per cent and her heart was only a little larger (c.t.r. 57 to $58 \%$ ) (0512).

The fifth, a boy aged 7, was at once better in his colour and could walk half a mile instead of 200 yards and get upstairs instead of being carried: his hæmoglobin was 119 instead of 148 per cent and his heart hardly changed in size (c.t.r. 50 to $51 \%$ ). Six years later, his improvement was maintained, but he was still very frail (0398).

The sixth, a boy aged 11, was somewhat improved and could get about more easily but could not walk much further: his hæmoglobin had fallen from 126 to 96 per cent, and his heart size increased somewhat (c.t.r. 48 to $53 \%$ ). Six years later he was about the same, but soon after he was admitted to hospital for hæmoptysis and was found to have tuberculosis of the lung, from which he has made a good recovery (0833; Fig. 1).

(b) Patients without a Continuous Murmur. The results were very good in the first two and good in the third and fourth. In all, the diagnosis of pulmonary atresia was supported by the findings 
at operation, the blood supply to the lungs being through a large anomalous artery in the first (see Fig. 3) and through bronchial arteries in the other three.

A girl, aged 10, was severely disabled but at right-sided thoracotomy in February 1948 no pulmonary artery could be found. In 1950, angiocardiography showed a curious artery on the right that encircled the hilum of the lung and appeared to come directly from the aorta. In 1953, she was rather worse and was most anxious that a second attempt should be made. At thoracotomy on the left side, clamping the pulmonary trunk caused no change, so Sir Russell Brock divided this and was then able to do an end-to-side subclavian-pulmonary anastomosis: the stoma produced, it was thought, might even prove to be too large. The result was excellent: her colour became normal ( $\mathrm{Hb} 142$ to $100 \%$ ) though slight cyanosis could still be detected in the tongue; and she was able to work and lead a normal life without an undue increase in the size of her heart (c.t.r. 48 to $55 \%$ ). She remained just as well for four years, till she was admitted to hospital with pyrexia and malaise: Staphylococcus aureus was grown on blood culture. She improved for a time with antibiotics, but then became drowsy with signs of a cerebral abscess, and died rather suddenly before anything else could be done.

At necropsy, there was a small cerebral abscess in the cortex of the right frontal lobe. There was some crumbling infected thrombus at and beyond the site of the anastomosis, and several infarcts in the lungs and in the spleen. The diagnosis of pulmonary atresia was confirmed, but unfortunately the unusual artery was not dissected out: the pulmonary artery beyond the anastomosis was thin-walled and dilated (0027). The cerebral abscess was thought to be a complication of her subacute bacterial endocarditis rather than the type that is so common without endocarditis in cyanotic congenital heart disease (Campbell, 1957).

The second patient, a boy aged 3, had a typical picture of pulmonary atresia but the artery beyond was adequate for an anastomosis. The result was excellent and he was able to get about all day and walk a mile. His hæmoglobin fell from 148 to 114 per cent (4 years) but had risen again to 131 per cent after eight years and his heart has become smaller again (c.t.r. 51 to 53 to $48 \%$ ) so that, although he is still as good clinically and has a loud continuous murmur, there is some doubt if the anastomosis is working as well as it had been (0638). [Another two years have passed without him losing any ground.]

A boy, aged 8, who was very severely disabled, was able to do much more but his colour did not improve as much as usual, his hæmoglobin averaged 136 instead of 149 per cent, and his heart was still small (c.t.r. 45 instead of $41 \%$ ). After eight years his improvement was maintained, but there had been some recent hæmoptysis, which proved not to be tuberculous. After ten years he is still at work (0447).

A boy, aged 5, had adequate pulmonary arteries for a good end-to-end anastomosis and was greatly improved in capacity and in colour. He could walk a mile instead of 100 yards and his hæmoglobin fell from 146 to 126 per cent without any undue increase in the size of the heart (c.t.r. 51 to $54 \%$ ). He was just as well four years later (P 123).

\section{Summary AND CONClusions}

The results of surgical treatment in 27 patients with pulmonary atresia have been described. All the completed operations were anastomotic ones, but often no artery suitable for an anastomosis could be found. The operative mortality proved very high and more than one third of the patients died, sometimes we think because the increased flow provided by the anastomosis was balanced by the loss from the almost inevitable division of many collateral arteries.

This high mortality might suggest that there is no place for this type of operation, but 15 per cent obtained extremely good results and another 22 per cent good results. On present experience operation would seem justified only when the heart is not much enlarged and some pulmonary artery, however small, can be seen on radiography or angiocardiography (see Fig. 3B, left side).

Generally the good results have been maintained for the six to eleven years that have elapsed. Only one of these patients has died, from a cerebral abscess following subacute bacterial endocarditis: one other has developed tuberculosis of the lung. So far the anastomotic channel has not closed in any of these patients, but it is unlikely that this hazard can be avoided for much longer, since it is an important cause of relapse after operation for Fallot's tetralogy.

The present position cannot be regarded as satisfactory. Whether many patients will prove suitable for direct repair of the atresia at open operation is uncertain, but this possibility must be considered further. 


\section{REFERENCES}

Abbott, M. E. (1936). Atlas of Congenital Heart Disease. New York.

Allanby, K. D., Brinton, W. D., Campbell, M., and Gardner, F. (1950). Guy's Hosp. Rep., 99, 110.

Campbell, M., and Gardner, F. (1950). Brit. Heart J., 12, 183.

- - , and Reynolds, G. (1952). Brit. Heart J., 14, 317.

, and Deuchar, D. (1953). Brit. med. J., 1, 349.

(1957). Lancet, 1, 111.

(1958). Brit. med. J., 2, 1179

East, T., and Barnard, W. G. (1938). Lancet, 1, 834.

Peacock, T. B. (1866). On Malformations of the Heart. 2nd ed., Churchill, London.

Taussig, H. B. (1947). Congenital Malformations of the Heart. Commonwealth Fund, New York, p. 169. and Bauerfeld, S. R. (1953). Ann. intern. Med., 38, 1.

White, B. D., McNamara, D. G., Bauerfeld, S. R., and Taussig, H. B. (1956) Circulation, 14, 512. 